\title{
POR ENTRE MEMÓRIAS DA VIDA ESCOLAR E ACADÊMICA: A FORMAÇÃO DOCENTE EM GEOGRAFIA EM QUESTÃO
}

\section{Between memories of school and academic life: the teacher education in Geography in question}

\author{
Victória Sabbado Menezes \\ Doutoranda em Geografia da UFRGS \\ victoriasabbado@gmail.com \\ Roselane Zordan Costella \\ Professora Doutora da Faculdade de Educação e do Programa de Pós-Graduação em Geografia \\ da UFRGS \\ professoracostella@gmail.com
}

Artigo enviado para publicação em 13/08/2019 e aceito em 05/11/2019

DOI: $10.12957 /$ tamoios.2019.44565

\begin{abstract}
Resumo
Este trabalho versa sobre a relação entre as memórias de ensino da vida escolar e acadêmica de licenciandos e professores formadores da licenciatura em Geografia. O distanciamento entre as memórias destes sujeitos (os primeiros, atreladas às memórias de escola e os últimos, às memórias de academia) acarreta uma formação fragilizada no tocante ao "ensinar a ensinar" e/ou "aprender a ensinar". Assim, geram-se repercussões sobre o ensino de Geografia escolar, o qual tende a manter-se de forma tradicional e reprodutivista, assentado no saber da tradição pedagógica. Ao considerar a formação docente como um processo contínuo e permanente ao longo de uma vida, entende-se que as memórias de ensino escolar atuam na construção de representações sobre a docência e orientam as práticas pedagógicas dos sujeitos. $\mathrm{O}$ caminho metodológico adotado consiste em revisão bibliográfica voltada ao ensino de Geografia e à formação docente, além de referenciais do campo da pesquisa (auto)biográfica. Logo, propõe-se que dispositivos formativos como narrativas (auto)biográficas e memoriais sejam inseridos na licenciatura visando provocar a reflexão coletiva entre professores formadores e licenciandos sobre seus percursos formativos e suas memórias de escola com o intento de ressignificar a formação inicial e o ensino de Geografia nas instituições escolares.
\end{abstract}

Palavras-chave: memória; formação docente; ensino; Geografia.

\begin{abstract}
This paper deals with the relationship between the teaching memories of the school and academic life of undergraduate students and Geography professors. The distance between the memories of these subjects (the first linked to school memories and, the last, to academy memories) leads to a weakened formation regarding "teaching to teach" and/or "learning to teach". Thus, repercussions on the teaching of school Geography are generated, which tends to remain traditional and reproductive, being based on the knowledge of the pedagogical tradition. When considering teacher education as a continuous and permanent process throughout a lifetime, it is understood that the memories of school teaching act out in the construction of representations about teaching and guide the pedagogical practices of the subjects. The methodological approach adopted consists of a bibliographic review which is focused on the teaching of Geography and teacher education, as well as references from the (self) biographical research field. Therefore, it is proposed that formative devices such as (self) biographical and memorial narratives may be inserted in the degree aiming at trigging the collective reflection between formative teachers and undergraduates about their formative pathways and their school memories in order to redefine initial education and teaching of Geography in school institutions.
\end{abstract}

Keywords: memory; teacher training; teaching; Geography. 


\section{Introdução}

O trabalho que ora se apresenta faz parte de uma pesquisa de doutorado em andamento do Programa de Pós-Graduação em Geografia da Universidade Federal do Rio Grande do Sul (UFRGS), na linha de pesquisa em Ensino de Geografia. Este se destina a problematizar a relação conflitante entre memórias docentes e discentes no processo de formação inicial de professores de Geografia. Cabem os questionamentos: de que memórias estão se referindo? Qual sua importância na formação docente? Quais efeitos podem produzir no ensino de Geografia na escola? Urge esclarecer, de imediato, que este trabalho está balizado em dois eixos: formação de professores e ensino de Geografia. Compreendem-se estes como indissociáveis, de modo que não é possível pensar a realidade do ensino de Geografia na contemporaneidade de forma desarticulada do processo formativo que é desencadeado na licenciatura.

O intuito desta produção textual acadêmico-científica consiste em discutir, de forma mais ampla, os saberes docentes mobilizados nas práticas de ensino no espaço escolar. O enfoque não está nos saberes científicos e racionais, mas sim naqueles referentes às representações dos professores, os quais são provenientes de suas memórias de ensino. Ou seja, as análises aqui empreendidas dedicam-se às memórias da vida escolar e acadêmica, as quais influenciam na identidade docente dos sujeitos e orientam seu fazer pedagógico. Pretende-se dialogar como estas memórias exercem influência sobre a professoralidade dos sujeitos, em quais momentos são resgatadas, por que se fazem presentes no exercício da prática profissional e como a formação inicial (licenciatura) lida com estas representações que os sujeitos carregam de vivências de ensino e de escola anteriores à formação universitária.

Em meio a estes diversos elementos apontados que conduzem as considerações que serão explicitadas no escopo deste trabalho intenta-se provocar a reflexão sobre a possibilidade de um conflito de memórias entre licenciandos e professores formadores da universidade. Isto é, levanta-se a hipótese de que há um distanciamento entre as memórias de ensino destes dois grupos de sujeitos, de maneira que os primeiros se aproximam de suas memórias de escola, ao passo que o outro grupo tem as memórias da academia mais vivas em suas lembranças. Assim, geram-se repercussões sobre a formação inicial, visto que os professores formadores tendem a voltar suas práticas pedagógicas para a pesquisa especializada, relegando a segundo plano a dimensão pedagógica, enquanto os licenciandos, com a dificuldade de estabelecer esta relação entre Geografia e Educação, apoiam-se em suas memórias de escola e reproduzem modelos, contribuindo para a manutenção de um ensino de Geografia mnemônico, conteudista e pouco reflexivo.

Portanto, este trabalho pretende discorrer sobre estas questões supracitadas inerentes ao ensino de Geografia e à formação de professores, além de levantar dúvidas e questionamentos que propiciem reflexões que contribuam para o conhecimento em constante movimento e ressignificação. Tem-se o intuito de socializar ideias e apontar incertezas que coloquem os professores do ensino básico, do ensino superior e os acadêmicos da licenciatura em diálogo efetivo visando a qualificação do ensino de Geografia escolar e da formação docente. Para tanto, é necessária uma postura aberta para novos conhecimentos e desconhecimentos.

\section{Caminho metodológico}

Para o desenvolvimento deste trabalho, a linha metodológica adotada pauta-se em uma revisão bibliográfica. Realizou-se um levantamento bibliográfico concernente 
aos principais eixos do trabalho (ensino de Geografia e formação docente) a fim de garantir um suporte teórico às afirmações apresentadas. Cabe salientar que esta é uma pesquisa de caráter qualitativo, de modo que não se baseia em dados estatísticos e quantitativos. O objeto de estudo são as memórias de licenciandos e professores formadores, o que denota o caráter subjetivo da investigação. Conforme Minayo (2011, p. 22), a pesquisa qualitativa "trabalha com o universo de significados, motivos, aspirações, crenças, valores e atitudes, o que corresponde a um espaço mais profundo das relações, dos processos e dos fenômenos que não podem ser reduzidos à operacionalização de variáveis".

Além dos teóricos do ensino de Geografia e da Educação, busca-se também referenciais no campo da pesquisa (auto)biográfica, a qual está atrelada às Ciências Sociais e Humanas e tem sua origem na segunda metade do século XX. Criada com a finalidade de estudar e analisar histórias de vida, este campo logo se tornou fértil ao ser explorado, dentre outras áreas, pelos estudos em Educação (PASSEGGI; ABRAHÃO; DELORY-MOMBERGER, 2012). Nas últimas décadas sua produção científica tem crescido de forma vertiginosa, visto que considera a trajetória de vida pessoal, escolar, acadêmica e profissional dos sujeitos para compreender sua constituição docente. Partese do princípio de que são muitos e os mais diversos os percursos formativos que atuam sobre a construção do ser docente.

Destarte, ao propor o estudo das memórias de ensino de escola e de universidade de licenciandos e professores formadores da licenciatura, está-se, inevitavelmente, lidando com um dos conceitos base da pesquisa (auto)biográfica, qual seja: a memória. A ênfase nas memórias das experiências de ensino e o pressuposto de que a formação docente é ampla e complexa, composta por saberes de diversas fontes e resultantes dos mais variados itinerários formativos configuram o presente trabalho em uma linha de pensamento que está em consonância com os fundamentos da pesquisa (auto)biográfica. Entende-se que a formação do/da professor/a ocorre ao longo de sua existência, é contínua e permanente. Logo, carrega marcas de vivências que também antecedem a formação universitária e a carreira profissional. Marcas estas extraídas de memórias que produzem representações sobre a docência e podem ser reafirmadas ou desmistificadas no âmbito da licenciatura. Eis aqui o desafio-obstáculo da formação de professores de Geografia.

\section{Memórias de ensino docentes e discentes no âmbito da formação inicial}

A profissão docente possui um aspecto peculiar: todos aqueles que decidem serem professores já conviveram com seu lócus de trabalho por muito tempo. Isso porque todos tiveram que frequentar a escola por, pelo menos, doze anos, se somar o período de Ensino Fundamental e Ensino Médio. Ainda que seja na condição de aluno/a, a inserção diária no cotidiano escolar faz com que os sujeitos criem representações sobre o ensino, a docência, a Geografia. Esta convivência com os profissionais que, no futuro, buscaremos ser possibilita a constituição de modelos do que seja um/a bom/boa professor/a, do que seja uma aula de Geografia interessante, do que seja um processo de ensino-aprendizagem envolvente e significativo. De acordo com Kaercher (2014, p. 35), "hoje, tenho claro que aprendemos a ser professores desde que nos tornamos alunos, desde muito crianças, portanto."

É digno de nota que dentre os educadores que tivemos ao longo da vida, haverá exemplos positivos e negativos. Todo/a professor/a tem a capacidade de deixar marcas em seus educandos, sejam aquelas que servem de inspiração ou aquelas que servem para que não queiramos repetir com nossos alunos. A constituição da identidade docente, a 
qual se caracteriza por um processo permanente de construção e transformação, é influenciada por diferentes experiências de vida nos mais diversos espaços e períodos da vida. Segundo Bolívar (2016, p. 270), "la identidad profesional docente se caracteriza por el conjunto de saberes y competências necesarias para practicar el oficio de la enseñanza y que, como tales, son reconocidas socialmente". Não é somente a licenciatura que forma professores. Não são somente os cursos de formação continuada que formam professores. Não é somente a prática profissional que forma professores. São todos estes elementos misturados aliados a outras questões que aqui referem-se a estas experiências de escola no papel de alunos.

Os elementos mencionados constituem o arcabouço de conhecimentos docentes. Trata-se dos saberes docentes que amparam o ser, estar, fazer professor/a. Segundo Tardif (2014), os saberes dos educadores não provêm de uma única fonte. São plurais e têm caráter temporal, visto que são construídos ao longo de uma história de vida e de uma carreira. No tocante aos saberes oriundos das experiências escolares anteriores à formação inicial, o autor destaca:

Em suma, antes mesmo de começarem a ensinar oficialmente, os professores já sabem, de muitas maneiras, o que é o ensino por causa de toda a sua história escolar anterior. Além disso, muitas pesquisas mostram que esse saber herdado da experiência escolar anterior é muito forte, que ele persiste através do tempo e que a formação universitária não consegue transformá-lo nem muito menos abalá-lo. (TARDIF, 2014, p. 20)

Esta história de vida escolar anterior está associada ao que Gauthier (1998) denomina de saber da tradição pedagógica. O autor sistematiza o conjunto de saberes dos professores, elencando-os em: saber disciplinar, saber curricular, saber da ação pedagógica, saber das ciências da educação, saber experiencial e saber da tradição pedagógica. Este último diz respeito à maneira tradicional de lecionar que está enraizada de forma hegemônica nas posturas docentes, visto que vem sendo reproduzida desde o século XVII. Dessa forma, "ela chegou até nós e povoa não somente as nossas recordações de infâncias, mas também uma boa parte do cotidiano das escolas atuais. Essa tradição pedagógica é o saber dar aulas que transparece numa espécie de intervalo da consciência" (GAUTHIER, 1998, p. 32).

Por conseguinte, as memórias de escola, em sua grande maioria, são marcadas pelo saber da tradição pedagógica. O que justifica a permanência de um ensino de Geografia na escola mecânico, pautado na memorização, pouco questionador e quase ausente de criticidade está relacionado à forte presença da tradição pedagógica no espaço escolar. O que chama a atenção é que os cursos de formação de professores de Geografia são regidos por discursos que visam a ressignificação das práticas de ensino em Geografia. As correntes mais progressistas e crítico-humanista da Geografia, bem como construtivista da Educação são enfatizadas na licenciatura. Os acadêmicos, por sua vez, têm contato com estes teóricos e estas linhas de pensamento que se contrapõe a um ensino de Geografia tradicional e conservador. Entretanto, percebe-se nos próprios estágios obrigatórios da licenciatura a dificuldade de desenvolver práticas alinhadas a este discurso.

Por que há esta dificuldade? Atribui-se a esta problemática a explicação de que, embora se estude tais linhas teóricas, os licenciandos pouco ou nada têm contato com práticas docentes que se amparem em tais perspectivas mais progressistas e construtivistas. Quais são os modelos e ou inspirações de professores críticoconstrutivistas que os acadêmicos possuem? Não raro, são escassos e, algumas vezes, até inexistentes. É digno de nota que esta percepção não se visualiza somente no espaço 
escolar, mas também no espaço universitário. Isso quer dizer que as práticas pedagógicas dos professores formadores das licenciaturas também devem ser revistas. Diante desse panorama e quando colocados em situações desafiadoras com seus alunos em sala de aula, os licenciandos (futuros professores) tendem a reproduzir o fazer pedagógico que já estão acostumados e a respeito do qual já sabem como agir e qual será a reação da turma. Dessa maneira, buscam-se as memórias de escola e as lembranças de como seus professores agiam em determinadas situações, como será aprofundado mais adiante. Isto revela o peso das memórias do ensino escolar na orientação das práticas de ensino dos futuros educadores.

No tocante ao conceito de memória, cabe esclarecer que esta é seletiva e corrigida. Há algumas situação e vivências que são enfatizadas e outras que são desconsideradas do baú de nossas memórias. Nossas reminiscências não abarcam tudo o que vivemos e experienciamos, senão nossa vida seria caótica. Logo, a memória abrange lembranças e esquecimentos. Além disso, as memórias, ao serem resgatadas no tempo presente são reconfiguradas e ressignificadas. $\mathrm{O}$ ato de narrar memórias não significa reproduzi-las exatamente da maneira como aconteceram, pois o tempo vivido no momento da narração, isto é, no presente está inserido em um determinado contexto que não é o mesmo de quando a situação rememorada de fato aconteceu. Este esclarecimento quanto ao exercício de narrar memórias é interessante, visto que "torna o momento presente, ou seja, o ato de lembrar, de narrar com o poder de reconfigurar o que ocorreu, o passado. Mas, a memória não só lembra, mas também silencia, que é diferente de esquecer, ou ainda, produz novos sentidos ao passado" (HONÓRIO FILHO, 2016, p. 356). Isso quer dizer que as memórias trazidas no tempo presente não são aleatórias, visto que sua evocação se explica pelas intencionalidades, vontades e interesses que se tem no agora. Assim, a memória é reconstituída, bem como lhe é atribuída novos sentidos e significados no presente.

O campo da pesquisa (auto)biográfica pode fornecer importantes contribuições para pensar a formação de professores, sobretudo ao propor a construção de narrativas (auto)biográficas, entendidas como um dispositivo formativo. Estas têm a memória como conceito central. Conforme Frison e Basso (2016, p. 367):

\footnotetext{
A narrativa é sempre um exercício que alia a memória da experiência vivida, o poder da interpretação do seu autor, outorgando a essa mesma experiência sentidos novos e singulares. Por meio das narrativas (auto)biográficas, é possível identificar, por exemplo, as características seguidas pelos professores, em sua própria dinâmica de formação, o que favorece a definição dos saberes necessários para o exercício da função de formador.
}

Nesse sentido, as narrativas (auto)biográficas constituem uma alternativa profícua ao permitir expor a história de vida dos professores que relatam suas memórias e seus percursos de formação. Resgatar estas memórias possibilita que as mesmas sejam problematizadas e refletidas. Desse modo, as narrativas articulam passado, presente e futuro, tendo em vista que recordam as experiências vividas, as ressignificam no tempo presente e projetam um futuro. Problematizar as memórias de escola, por exemplo, podem acarretar na desconstrução de representações e ideias pré-estabelecidas que estavam consolidadas nas mentes dos sujeitos. Ao desconstruir estas representações, as quais orientam a conduta dos sujeitos professores, tem-se o ponto de partida para a transformação de suas práticas pedagógicas.

Deve-se salientar a importância de discutir as memórias de ensino, pois são potentes ao orientar o fazer docente. Indaga-se: por que estas memórias, que predominantemente assentam-se no saber da tradição pedagógica, seguem vivas e em 
permanente difusão? Com aporte teórico em Halbwachs (2006) estas memórias ainda fortemente presentes nas mentes dos sujeitos se explicam, pois não se referem somente às memórias individuais. As mesmas constituem o que o autor nomeia de memória coletiva, uma vez que faz parte de um imaginário social. Pode-se considerar que "a memória coletiva tira sua força e sua duração por ter como base um conjunto de pessoas, são os indivíduos que se lembram, enquanto integrantes do grupo" (HALBWACHS, 2006, p. 69). Destarte, as vivências de escola semelhantes entre os sujeitos através de um ensino marcadamente positivista, descritivo e classificatório compõem as memórias individuais que se associam e configuram uma memória coletiva.

Não raro esta memória é ativada quando o sujeito se depara com situações desafiantes no contexto concreto do seu trabalho pedagógico em sala de aula, como mencionado anteriormente. Isso pode ser claramente observado com os licenciandos quando estão desenvolvendo seu estágio de regência. Apesar de terem estudado e debatido ao longo do curso sobre o construtivismo, por exemplo, e manifestarem em seus discursos o interesse por esta linha epistemológica da Educação, na prática "não sabem que decisões tomar frente às situações mais conflitantes e, por isso, presos a esquemas clássicos e tradicionais, acabam por reproduzir condutas heterônomas (autoritárias), procurando dar conta de uma situação sobre a qual parece terem perdido o controle" (KEBACH, 2010, p. 44).

Contudo, por que assumem estas condutas? Por que não exercem a vertente defendida do construtivismo em sua prática de ensino? No momento de tensão e angústia, em que o/a professor/a não sabe lidar com situações problemáticas em sala de aula, recorre às suas memórias de escola. Como agiam meus professores? Que posturas assumiam? Isso ocorre porque a educação e formação de professores se constroem também pelo exemplo. Os exemplos que a maioria dos alunos, futuros professores, teve foi de educadores que desenvolviam sua ação pedagógica amparada na epistemologia empirista e na pedagogia diretiva (BECKER, 2001). Assim, esta memória, que é individual e também coletiva, tende a se propagar. Cabe a ressalva de que a memória resgatada não busca refúgio. Ou seja, o ato do/da professor/a de se apropriar de suas memórias de ensino escolar para resolver desafios cotidianos de sua prática profissional não ocorre de forma tão nítida e consciente como aqui explicitado. Além disso, também não busca referência em uma única vivência passada. As memórias não são pontuais, visto que resultam de uma rede de relações que abrangem diversas situações vividas ao longo de uma existência, de uma trajetória. Logo, não se trata de uma simplificação e/ou de uma transposição mecânica do que se experienciou para o que se faz, pois o processo é complexo e, portanto, contraditório.

Diante disso, não se pode deixar de questionar o porquê de se recorrer às memórias de escola nestas situações desafiadoras da docência. Não haveria outras saídas e/ou alternativas? O cerne desta problemática está na formação inicial docente. O que se verifica é que "os professores frutos dessas universidades sabem muito Geografia e Matemática, mas sabem pouco como transformar os conhecimentos acadêmicos em conhecimentos de sala de aula na educação básica" (COSTELLA, 2013, p. 63). Esta realidade não rara está atrelada ao saber compartimentado vigente no ambiente acadêmico. A ênfase na pesquisa especializada e na fragmentação da ciência geográfica faz com que a preocupação com o ensino e a pesquisa em ensino seja relegada a segundo plano. Ao mesmo tempo, as disciplinas da Faculdade de Educação dedicam-se ao estudo dos pressupostos teóricos desta área. Sabe-se de Geografia e sabe-se de Educação, mas pouco se conhece sobre ensino de Geografia. 
Se as memórias de escola são vivas na mente dos licenciandos, por que a formação acadêmica não consegue fazer frente a estas representações construídas sobre docência, ensino e Geografia? No curso de licenciatura, os acadêmicos são introduzidos a pensar cientificamente sua profissão e os pressupostos teóricos, epistemológicos e metodológicos que assentam o trabalho docente. Mesmo com todo esse arcabouço de conhecimentos que se tem contato na universidade, as representações e crenças oriundas das experiências anteriores ainda possuem uma carga considerável de importância.

A esta problemática chama-se atenção para dois pontos. $\mathrm{O}$ primeiro diz respeito às concepções e práticas dos professores universitários. Não se pode questionar a postura dos licenciandos e futuros professores do ensino básico sem voltar o olhar aos professores formadores. Se há dificuldade de desenvolver um ensino de Geografia crítico-humanista e construtivista nas instituições escolares e a tradição pedagógica permanece enraizada nas ações educativas isso se deve, entre outros fatores, a falta de exemplos de outros fazeres pedagógicos distintos a este hegemônico. Quando se refere a esta falta de exemplos que possam inspirar os professores da educação básica a renovarem suas práticas está se apontando não somente a responsabilidade da escola, mas, sobretudo, a responsabilidade dos professores formadores da universidade.

Torna-se necessário que as pesquisas também estejam voltadas para a formação docente, com ênfase nas práticas de ensino de professores formadores. É preciso que estes façam uma auto-avaliação, uma auto-crítica e uma auto-reflexão. Tal intenção pressupõe "a ideia de outra universidade que forme professores, cursos de licenciatura que compreendam o papel da Geografia para além dos conceitos e pesquisa especializadas, não desmerecendo-as, mas atrelando-as ao cotidiano do professor da escola" (COSTELLA, 2018, p. 58). Não basta que a licenciatura seja composta por ótimos geógrafos; é premente possuir bons professores. Nesse sentido, os princípios que regem a atuação docente nos cursos de graduação de formação docente devem ser questionados. A humildade intelectual deve fazer parte deste contexto de formação de futuros professores. Para tanto, a própria ideia de conhecimento científico como o único que apresenta validade e é legítimo deve ser posta em questão. Aqui está o segundo ponto que se pretende destacar: há saberes não-racionais que influenciam na formação dos educadores e produzem impactos sobre sua identidade docente. Já passou do momento da universidade, ainda arraigada ao paradigma da ciência moderna, considerálos.

No que concerne à constituição da identidade docente, Cavalcanti (2012, p. 21) assevera:

\begin{abstract}
Dessa perspectiva, é necessário reconhecer que a construção da identidade é um processo sócio-histórico, que tem uma existência mais longa que a própria formação inicial e que a carreira do magistério. Nela, têm papel acentuado as representações sociais, as crenças dos professores sobre sua profissão, que vêm das próprias representações ao longo da vida. Mas a identidade vem também da experiência que o professor adquire em sua prática escolar cotidiana e na cultura da escola. Por ser um processo social que define papéis sociais de diferentes sujeitos, que são, por sua vez, situados histórico e socialmente, é importante entende-lo sempre em construção, não fechado e unidimensional. Portanto, há elementos relevantes, que se constituem como referentes para a construção da identidade da docência: a história de vida, a formação e a prática pedagógica.
\end{abstract}

Sendo assim, para além da formação e do fazer pedagógico, a história de vida é fundamental para compreender as trilhas percorridas e os rumos de cada sujeito professor/a. As concepções dos professores, suas formas de atuar, de exercer a 
profissão, de buscar sua qualificação estão relacionadas às experiências que tiveram e têm ao longo de uma vida nos mais diversos espaços que circularam. Dessa maneira, quem o sujeito é como pessoa interfere no seu ser professor/a, assim como o modo como se coloca enquanto docente se reflete na sua identidade pessoal. Por isso, não se pode desvincular o ser pessoal do ser profissional docente. Ambos estão ligados de forma indissociável.

As memórias das vivências principalmente nos espaços de ensino influem nas representações construídas pelos educadores sobre sua profissão. Representações estas que apresentam uma função importante na constituição da identidade dos mesmos, conforme apontou Cavalcanti (2012). Contudo, levanta-se a ideia de que um dos desafios-obstáculos da formação inicial está no conflito de memórias entre professores formadores e licenciandos. Explica-se: considera-se que as memórias dos acadêmicos sobre ensino se aproximam de suas vivências na escola, ao passo que as memórias dos professores universitários ligam-se mais às experiências de quando eram alunos na academia. Diante disso, Costella (2018, p. 55) elenca alguns pontos nesta mesma linha de pensamento que problematizam a formação inicial docente:

Como um professor da universidade prepara suas aulas com memória de alunos que trabalharão com jovens, ainda em processo de construção hipotética do conhecimento. Como são feitas as súmulas das disciplinas que compõe um curso de licenciatura. Como os professores da licenciatura acompanham, avaliam ou orientam trabalhos em ensino.

Verifica-se um distanciamento de memórias entre acadêmicos e professores universitários que resulta em um descompasso na formação dos educadores. Os professores da universidade, sobretudo das disciplinas específicas da Geografia, organizam e desenvolvem suas aulas para um/a aluno/a com pensamento já abstrato. Entretanto, este ensinará para alunos do ensino básico, os quais ainda se encontram em processo de desenvolvimento cognitivo marcado pelo pensamento concreto. Cria-se, assim, uma problemática na licenciatura: como ensinar a ensinar? Por isso, os acadêmicos sabem muito de Geografia e de Educação, mas não sabem como ensinar Geografia na escola. Da mesma forma, a maioria dos professores formadores sabe ensinar Geografia aos acadêmicos pela via da pesquisa especializada, porém possuem dificuldades em ensinar professores a ensinarem Geografia nas instituições escolares. Como resultado os licenciandos reproduzem em suas práticas pedagógicas o que vivenciaram quando eram alunos na escola básica (a tradição pedagógica) e os professores universitários repetem as práticas de ensino que tiveram na universidade na condição de acadêmicos. Logo, torna-se imprescindível buscar alternativas que visem enfrentar este desafio-obstáculo presente nas licenciaturas em Geografia.

\section{Considerações finais}

A partir das análises e reflexões tecidas ao longo do trabalho, observou-se que as licenciaturas em Geografia são atravessadas por um conjunto de questões que demonstram a necessidade de repensá-la. Isso se justifica pelo fato de suas problemáticas se reverberarem no ensino de Geografia na escola. É consenso na comunidade acadêmica de que as práticas de ensino deste componente curricular ainda assentam-se num empirismo exacerbado, na informação enciclopédica, na descrição e memorização dos conteúdos, o que pouco contribui para que os sujeitos alunos se reconheçam na realidade sócio-espacial de que fazem parte e se coloquem de forma atuante no seu espaço vivido. É inquietante pensar que a potencialidade da Geografia 
em colaborar para a formação de cidadãos críticos, autônomos, criativos e reflexivos não tem sido explorada de forma intensa nas escolas, ainda mais no contexto hodierno caracterizado por um pacote de retrocessos políticos e sociais. Tal fato não se dissocia da formação acadêmica realizada no âmbito da licenciatura.

Ressignifcar o ensino de Geografia na escola pressupõe ressignificar a formação de professores de Geografia. Para tanto, os esforços aqui empreendidos estiveram voltados a este intuito maior. $\mathrm{O}$ enfoque apresentado na presente produção centrou-se na problemática das memórias docentes e discentes no âmbito da formação inicial de professores. Atribui-se a este distanciamento de memórias um dos graves entraves presente na licenciatura. Deve-se esclarecer que não se trata de um fenômeno isolado, tendo em vista que a presença marcante das memórias de ensino dos sujeitos nas suas mentes e que acarretam na reprodução de modelos assentados na tradição pedagógica estão associadas a outros fatores que também evidenciam as fragilidades da formação inicial, como o privilégio do conhecimento científico em detrimento de outros saberes (histórias de vida, por exemplo), o modelo aplicacionista do conhecimento (separação teoria-prática), a compartimentação do saber, a especialização do conhecimento, a distância entre universidade-escola, entre outros.

Portanto, propõe-se que para superar o desafio-obstáculo abordado ao longo deste trabalho seja adotado o método (auto)biográfico na formação inicial de professores. Torna-se premente desconstruir representações e crenças que os sujeitos (professores e licenciandos) carregam acerca do ensino, da figura docente e da Geografia. É preciso buscar as histórias de vida e colocá-las em análise para que os saberes provenientes das experiências anteriores à formação inicial sejam discutidos à luz dos referencias teóricos pertinentes. As memórias de escola e de universidade exercem um papel relevante na constituição da identidade docente e na condução das práticas pedagógicas dos sujeitos professores, seja de escola ou de universidade. Desconsiderá-las dos processos de formação dos educadores seria um erro crasso.

Por conseguinte, sugere-se que os memoriais de formação e as narrativas (auto)biográficas tornem-se práticas recorrentes no interior da licenciatura em Geografia. Estes podem ser concebidos como dispositivos formativos, conforme assevera Abrahão (2016) e Portugal (2015). Para a primeira autora, uma das maiores potencialidades do memorial de formação está na sua socialização com os demais professores em formação, de modo que a troca com os pares permite revisitar, remodelar e produzir novos sentidos ao que havia composto no memorial de formação. Portugal acrescenta que os memoriais e as narrativas (auto)biográficas revelam a história de vida dos sujeitos e faz com que esta, por si só, já constitua uma das fontes da formação do professor. Nesse sentido, defende-se uma ressignificação das licenciaturas em Geografia, de modo que os dispositivos formativos mencionados compreendem uma alternativa profícua a fim de que tanto acadêmicos quanto professores formadores busquem a auto-reflexão, a problematização do conjunto de saberes-fazeres docentes e estejam abertos para rever concepções epistemológicas e pedagógicas e transformar suas práticas.

\section{Referências bibliográficas}

ABRAHÃO, Maria Helena Menna Barreto. Intencionalidade, reflexividade, experiência e identidade em pesquisa (auto)biográfica: dimensões epistemo-empíricas em narrativas de formação. In: BRAGANÇA, Inês Ferreira de Souza; ABRAHÃO, Maria Helena Menna; FERREIRA, Márcia Santos. Perspectivas epistêmico-metodológicas da pesquisa (auto)biográfica. Curitiba: CRV, 2016. (p. 29-50). 
BECKER, Fernando. Educação e construção do conhecimento. Porto Alegre: Artmed Editora, 2001.

BOLÍVAR, Antonio. Las historias de vida y construcción de identidades profesionales. In: ABRAHÃO, Maria Helena Menna Barreto; FRISON, Lourdes Maria Bragagnolo; BARREIRO, Cristhianny Bento. (Orgs.). A nova aventura (auto)biográfica: tomo I. Porto Alegre: EDIPUCRS, 2016. (p. 251-287).

CAVALCANTI, Lana de Souza. O ensino de geografia na escola. Campinas, SP: Papirus, 2012.

COSTELLA, Roselane Zordan. Movimentos para (não) dar aulas de geografia e sim capacitar o aluno para diferentes leituras. In: CASTROGIOVANNI, Antonio Carlos.; TONINI, Ivaine Maria.; KAERCHER, Nestor André (Orgs.). Movimentos no ensinar geografia. Porto Alegre: Imprensa Livre: Compasso Lugar-Cultura, 2013. (p. 63-74).

COSTELLA, Roselane Zordan. Espaços ausentes e não inexistentes na Geografia escolar. In: CASTROGIOVANNI, Antonio Carlos (Orgs. et. al.). Movimentos para ensinar geografia - oscilações. Goiânia: C\&A Alfa Comunicação, 2018. (p. 47-59).

FRISON, Lourdes Maria Bragagnolo; BASSO, Fabiane Puntel. Construções identitárias reveladas em trabalhos com narrativas (auto)biográficas. In: ABRAHÃO, Maria Helena Menna Barreto; FRISON, Lourdes Maria Bragagnolo; BARREIRO, Cristhianny Bento. (Orgs.). A nova aventura (auto)biográfica: tomo I. Porto Alegre: EDIPUCRS, 2016. (p. 363-388).

GAUTHIER, Clermont [et al.]. Por uma teoria da pedagogia: pesquisas contemporâneas sobre o saber docente. Ijuí: Ed. UNIJUÍ, 1998.

HALBWACHS, Maurice. A memória coletiva. Tradução de Beatriz Sidou. São Paulo: Centauro, 2006.

HONÓRIO FILHO, Wolney. O uso da memória em eixos de comunicação dos CIPAS 2004-2012. In: ABRAHÃO, Maria Helena Menna Barreto; FRISON, Lourdes Maria Bragagnolo; BARREIRO, Cristhianny Bento. (Orgs.). A nova aventura (auto)biográfica: tomo I. Porto Alegre: EDIPUCRS, 2016. (p. 345-362).

KAERCHER, Nestor André. Se a geografia escolar é um pastel de vento o gato come a geografia crítica. Porto Alegre: Evangraf, 2014.

KEBACH, Patrícia Fernanda. O professor construtivista: um pesquisador em ação. In: BECKER, Fernando; MARQUES, Tania Beatriz Iwaszko (Orgs.). Ser professor é ser pesquisador. Porto Alegre: Mediação, 2010. (p. 43-54).

MINAYO, Maria Cecília de Souza (Org.). Pesquisa social: teoria, método e criatividade. 30. ed. Petrópolis: Vozes, 2011.

PASSEGGI, Maria da Conceição; ABRAHÃO, Maria Helena Menna Barreto; DELORY-MOMBERGER, Christine. Reabrir o passado, inventar o devir: a inenarrável 
condição biográfica do ser. In: PASSEGGI, Maria da Conceição; ABRAHÃO, Maria Helena Menna (Orgs.). Dimensões epistemológicas e metodológicas da pesquisa (auto)biográfica: Tomo II. Natal: EDUFRN; Porto Alegre: EDIPUCRS; Salvador: EDUNEB, 2012. (p. 29-57).

PORTUGAL, Jussara Fraga. Memoriais, diários e portfólios: narrativas autobiográficas e formação docente. In: PORTUGAL, Jussara Fraga; CHAIGAR, Vânia Alves Martins (Orgs.). Ensino e pesquisa em educação geográfica: memórias, histórias de vida e narrativas docentes. Salvador: EDUFBA, 2015. (p. 43-72).

TARDIF, Maurice. Saberes docentes e formação profissional. 16. Ed. Petrópolis, RJ: Vozes, 2014. 